\title{
Diretrizes para aplicação de superfícies paramétricas baseadas em luz e sombra
}

\section{Guidelines for application of parametric surfaces based on light and shade}

\author{
Giovani De Luca \\ Professor especialista na \\ Universidade do Extremo Sul \\ Catarinense - UNESC. \\ Mestrando do \\ PGDesign/UFRGS - Brasil. \\ giovanideluca@unesc.net
}

\section{Roberta Bertoletti}

Mestre em Arquitetura pela Universidade Federal de Santa Catarina - UFSC. Professora no Curso de Arquitetura e Urbanismo da FSFA. Doutoranda do PGDesign/UFRGS - Brasil. roberta.bertoletti@ufrgs.br

\section{Underléa Miotto Bruscato}

Universidade Federal do Rio Grande do Sul - UFRGS Doutora em Arquitetura. Professora no PGDesign/UFRGS - Brasil arq.leiab@gmail.com

\begin{abstract}
RESUMO
Desde os relógios solares da Antiguidade até os painéis fotovoltaicos atuais, o homem procura interagir com a luz. Seguindo a mesma intuição de usar esse recurso renovável, essa pesquisa apresenta um estudo de criação de imagens bi cromáticas através da luz e sombra. Na arquitetura, o uso de texturas em conjunto com a iluminação vem sendo cada vez mais usado como elemento decorativo em revestimentos, painéis, murais e fachadas. Com o objetivo de traçar diretrizes para otimizar a aplicação dessas texturas, foram selecionados parâmetros de inclinação do módulo, complexidade da imagem e opacidade do material. Com a ajuda do softwareRhinoceros e o plug-inGrasshopper, esses parâmetros foram testados em todas as possíveis combinações e simulados em ambientes internos e externos. Ao final do estudo, foi possível dar diretrizes de dimensionamento de painéis para os tipos de ambientes, inclinação ideal do módulo para melhor contraste entre figura e fundo, dimensões mínimas para que textos sejam legíveis e o melhor nível de opacidade na escolha dos materiais. Esse material poderá servir para arquitetos, designers e decoradores que necessitam representar imagens, textos ou passar qualquer informação através de texturas, luz e sombra.
\end{abstract}

Palavras-chave: superfícies paramétricas; grasshopper; luz e sombra.

\begin{abstract}
From the ancient solar clocks to the current photovoltaic panels, man seeks to interact with light. Following the same intuition of using renewable resources, this article presents a study with the creation of bi chromatic images through light and shadow. In architecture, the use of textures in conjunction with lighting has been increasingly used as a decorative element in coatings, panels, murals and facades. With the purpose of proposing guidelines to optimize the application of these textures, parameters of module inclination, image complexity and opacity of the material were selected. With the aid of Rhinoceros software and the Grasshopper plug-in, these parameters were tested in all possible combinations and simulated in indoor and outdoor environments. At the end of the study, it was possible to indicate the sizing of panels for the types of environments, the ideal slope of the module for better contrast between figure and background, the minimum dimensions for texts to be readable and the best level of opacity in the choice of materials. The findings can be used for architects, designers and decorators who need to represent images, texts or to pass any information through textures, light and shade.
\end{abstract}

Keywords: parametric surfaces; grasshopper; light and shadow. 


\section{INTRODUÇÃO}

Desde a Antiguidade o homem usa a luz como ferramenta a seu favor. Iluminação residencial, fotografia e relógio solar são alguns dos exemplos. Este último, que nos seus modelos mais simples projetava sua sombra em um plano devidamente marcado, indicava as horas e minutos. Nos dias de hoje, não necessitamos mais de relógios solares, porém ainda se pode utilizar a projeção da luz em nosso favor para algumas finalidades práticas.

A partir desse pensamento, o presente artigo apresenta o resultado de uma das atividades realizadas para a disciplina de Fabricação Digital como Ferramenta de Projeto oferecida peloPrograma de Pós Graduação em Design de uma Universidade do Sul do Brasil, onde analisa a representação de textos e imagens em superfícies através da luz e sombra. Esse estudo visa apresentar o desenvolvimento de um produto com superfícies paramétricas e propor algumas diretrizes para aplicação dessa técnica.

Para a elaboração do trabalho foi utilizado o plugin de modelagem paramétrica visual Grasshopper. E, ao final do estudo, são apresentadas diretrizes de aplicação destas superfícies paramétricas em ambientes internos e externos.

\section{USO DE SUPERFÍCIES BASEADAS EM LUZ E SOMBRA}

Em um ambiente, existem elementos que podem influenciar o bemestar físico e emocional do usuário, trazendo benefícios a sua saúde e afetar de maneira positiva o seu comportamento. Dentre esses elementos, que causam estímulos sensoriais, destacam-se a textura, a luz e a forma.

A textura sentida pelo sistema óptico pode contribuir para o bemestar do indivíduo. Num ambiente, as diferentes texturas proporcionam conforto ao espaço.

“A qualidade tátil do espaço pode ser enriquecida pelo uso de tratamentos diferenciados para as superfícies, como variedade de acabamentos [...], proporcionando conforto". (VASCONCELOS, 2004, p.58).

Para a utilização de texturas e revestimentos em um ambiente residencial, por exemplo, não existem normas a serem seguidas. E os mesmos elementos podem isolar acusticamente o ambiente como: revestimentos em madeira, painéis, carpetes, podendo aumentar a qualidade do espaço, proporcionando a sensação de aconchego e conforto.

A textura, luz e forma estão diretamente associados aos componentes promotores do bem-estar estabelecidos por Ulrich (1995): o suporte social, as distrações positivas e o controle do ambiente que diminuem o estresse dos usuários. Nas distrações positivas, destaca-se ainda a relação interior versus exterior, que é positiva ao indivíduo, pois fornece 
muitos estímulos (como por exemplo a luz, evidenciando a forma de uma edificação).

"A arquitetura é o jogo sábio, correto e magnífico dos volumes sob a luz. Nossos olhos são feitos para ver formas sob luz; as sombras e os claros revelam as formas [...]" (LE CORBUSIER, 2004, p.13).

Pensando nisso, foi realizada uma busca de possíveis aplicações e usos de superfícies parametrizadas baseadas em luz e sombra. Observa-se que os revestimentos podem ser utilizados em ambientes internos (como na figura 1) e também em ambientes externos, como mostram as figuras 2 , 3 e 4.

Figura 1: Revestimentos em pedra ardósia com efeitos de luz e sombra.
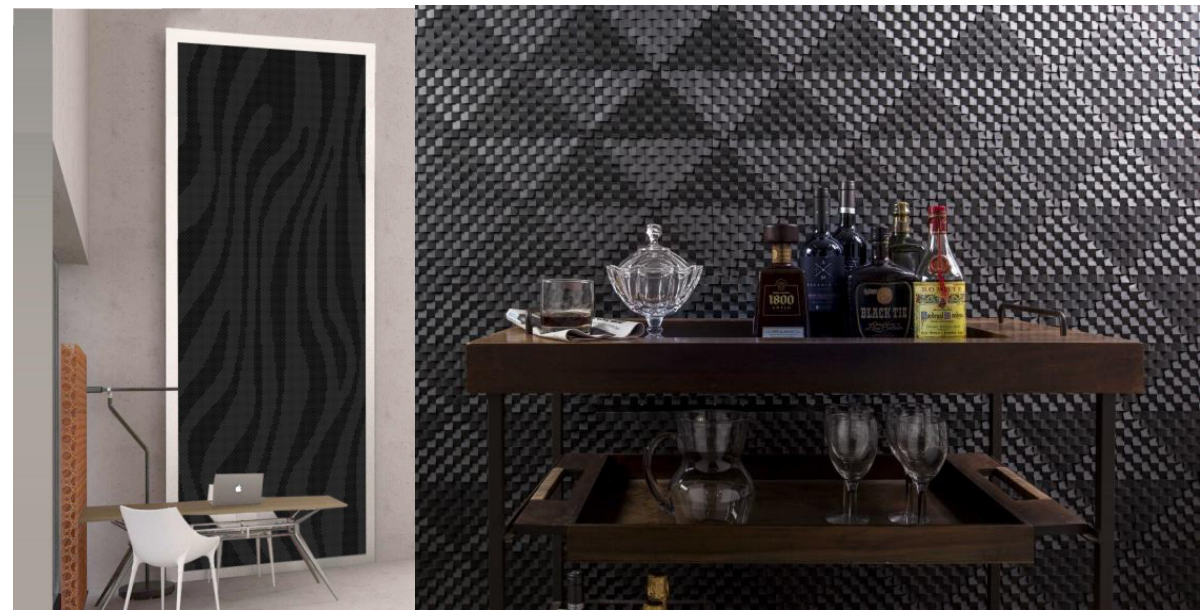

Fonte: Mosarte Revestimentos Especiais (2016).

Nas figuras 2 e 3, observa-se a utilização de revestimentos cerâmicos em suas superfícies e a partir da luz e sombra são geradas as imagens.

Figura 2: Exemplo de fachadas com revestimento cerâmico - Faculdade Fontys Sports/Mecanoo, em Eindhoven, na Holanda.

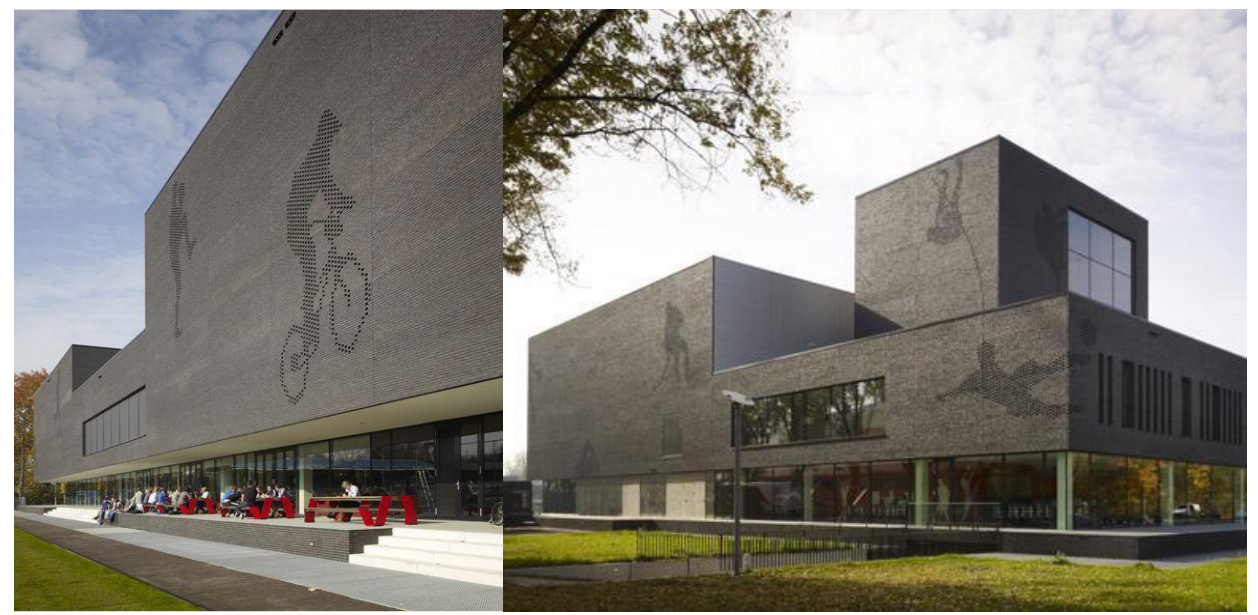

Fonte: ArchDaily (2013) 
Figura 3: Edifício da Sede Vodafone, Lisboa - Portugal.

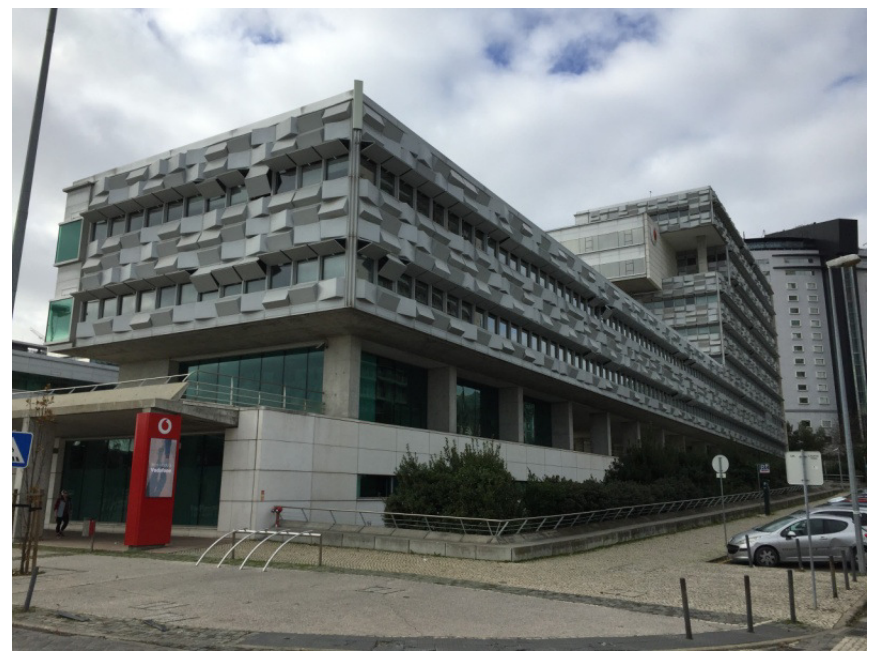

Fonte: acervo dos pesquisadores (2018).

Figura 4: Painel em pré-moldado na fachada da edificação.

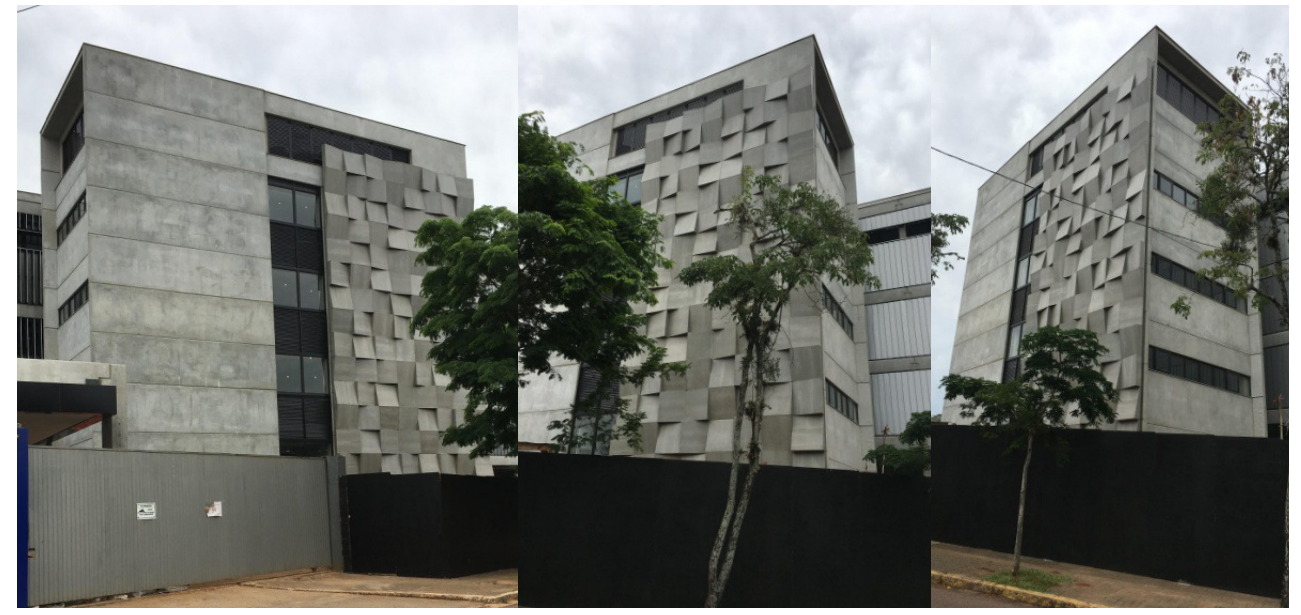

Fonte: acervo dos pesquisadores (2018).

Atualmente, o uso de painéis metálicos paramétricos nas fachadas tem se destacado. Esses painéis podem ser aplicados em superfícies curvas ou planas e por isso os tornam versáteis, podendo contribuir para o conforto e estética de uma edificação.

"Geometrias curvilíneas complexas são produzidas com a mesma facilidade que as geometrias de formas planas e formas cilíndricas, esféricas ou cônicas" (KOLAREVIC, 2003).

Na figura 5, abaixo, têm-se alguns exemplos de fachadas que utilizam painéis metálicos com chapa perfurada (com o efeito de luz e sombra - na superfície lisa tem-se a reflexão da luz e na superfície vazada a sombra). 
Figura 5: Exemplos de fachadas metálicas.

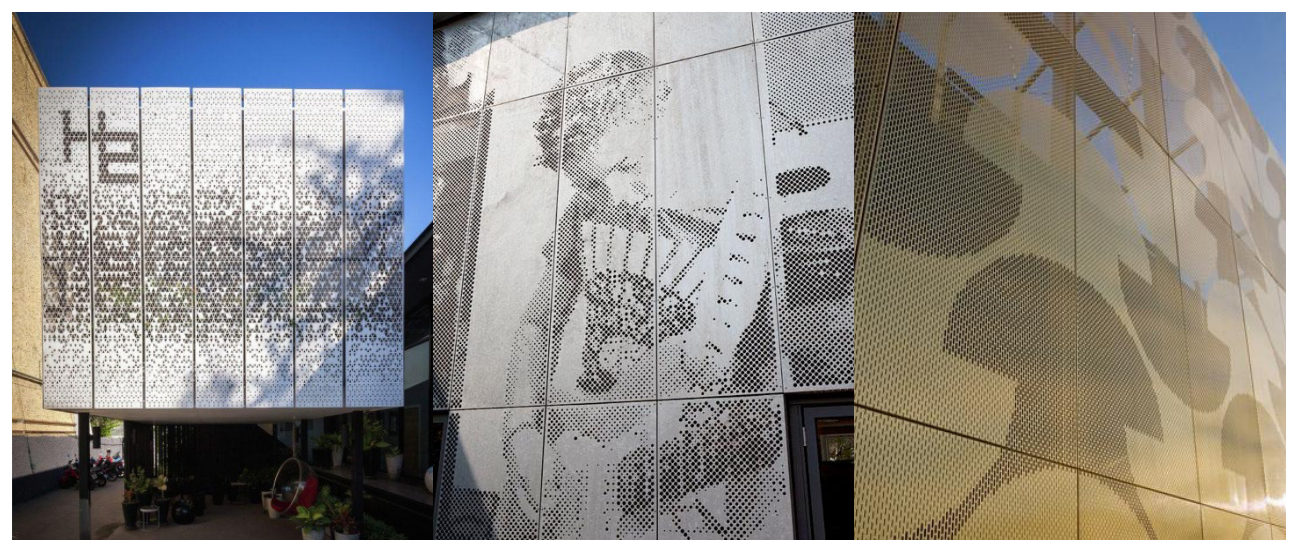

Fonte: StylePark - Photos(C RGIM (2018).

0 algoritmo, que é o objetivo deste estudo, pode ser aplicado em situações como as mostradas nas figuras 1, 2, 3 e 4, assim como outras soluções aplicadas em produtos, comunicação e arquitetura, pois segundo Woodbury (2010), "fazer alterações em um modelo pode ser difícil. Mesmo mudando uma dimensão pode exigir ajustar muitas outras partes e todo esse retrabalho é manual. Quanto mais complexo o modelo, mais trabalho pode ser acarretado." Com revestimentos com essa dimensão e complexidade, se faz necessário um algoritmo que gere essas soluções.

\section{MÉTODOS E TÉCNICAS}

A pesquisa é de caráter experimental, que "consiste essencialmente em submeter os objetos de estudo à influência de certas variáveis, em condições controladas e conhecidas pelo investigador, para observar os resultados que a variável produz no objeto" (GIL, 2002, p. 34-35).

Para a realização desse estudo foram utilizados três procedimentos distintos: 1 - determinação dos parâmetros a serem pesquisados, 2 apresenta o Grasshopper e o desenvolvimento (construção) do algoritmo e 3 - geração das combinações de parâmetros. 0 primeiro buscou dados para definir os parâmetros que seriam usados, já o segundo, foco deste artigo, procurou desenvolver o algoritmo que atendesse aos objetivos definidos. 0 terceiro gerou dezesseis combinações diferentes, que ao contrário da modelagem CAD tradicional, a modelagem paramétrica permitiu testar todas as combinações possíveis, obtendo assim diferentes resultados. Esses resultados foram analisados para a proposta de diretrizes de aplicação do produto.

Justifica-se a escolha destes diferentes métodos, pois sua combinação pode minimizar as possíveis limitações de cada um, complementando-os. 


\subsection{Seleção de parâmetros}

Antes de iniciar a construção do algoritmo, foram realizados alguns esboços à mão livre (figura 6). "O projeto paramétrico depende da definição de relacionamentos e da disposição (e habilidade) do projetista de considerar a fase de definição de relacionamento como parte integrante do processo de design mais amplo. Inicialmente, exige que o designer retorna um passo da atividade direta do design e foca na lógica que une o design" (WOODBURY, 2010).

Figura 6: Esboços para a seleção dos parâmetros e construção do algoritmo.
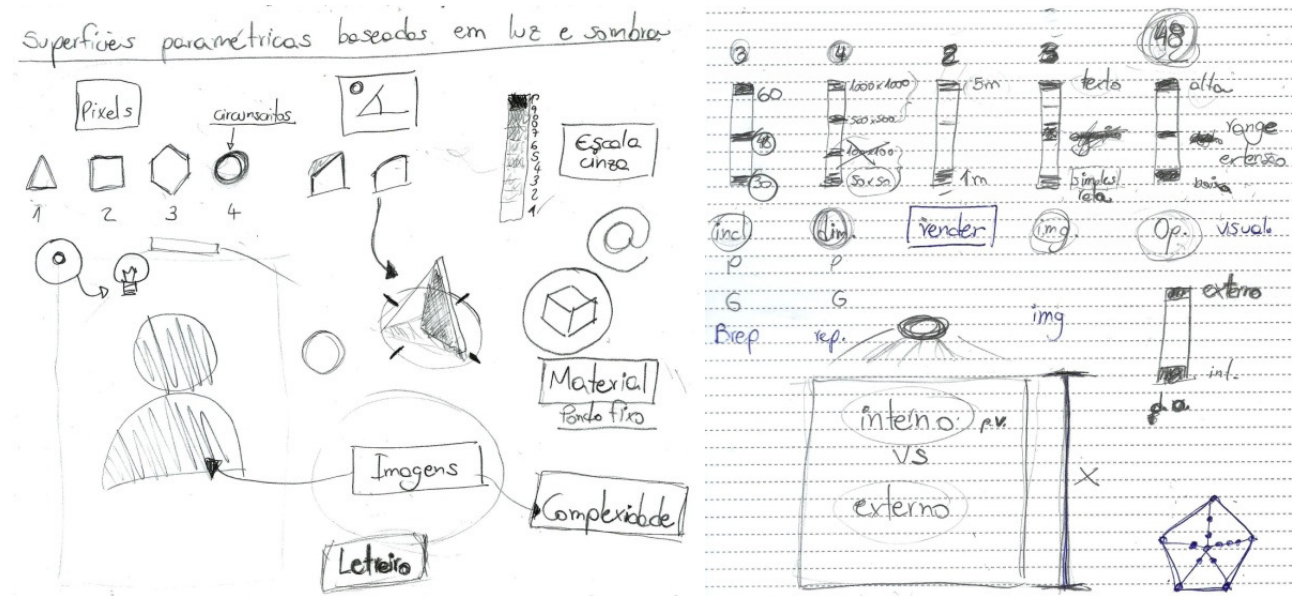

Fonte: elaborada pelos autores (2018).

Depois desta etapa de representação gráfica e foco na lógica das superfícies paramétricas, foi possível definir a unidade mínima (módulo) e possíveis elementos que poderiam se tornar parâmetros (figura 7).

Figura 7: Parâmetros selecionados.

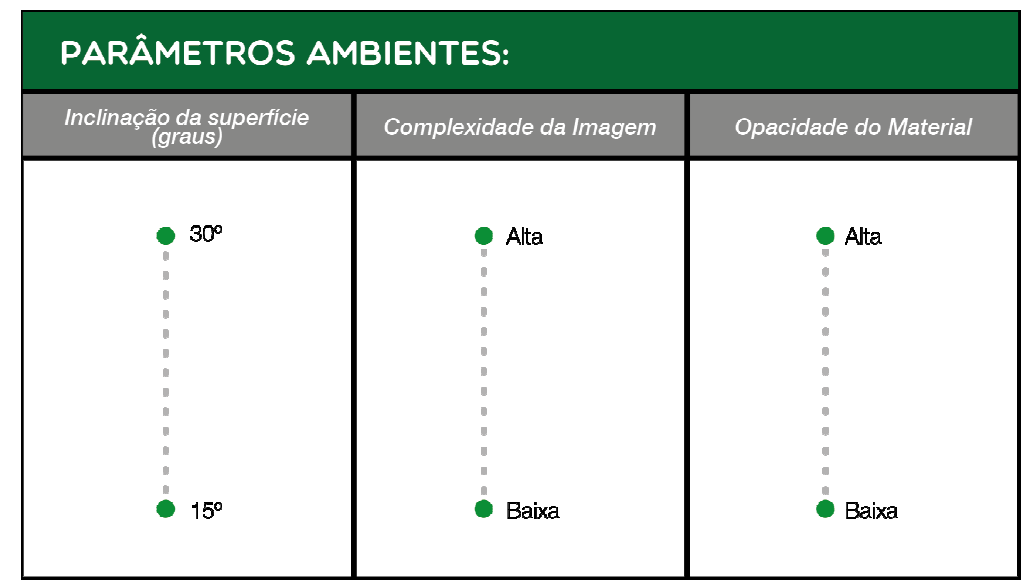

Fonte: elaborada pelos autores (2018). 
O primeiro parâmetro, a inclinação da superfície, está relacionada ao módulo, que tem uma forma trapezoidal, de base quadrada e, um plano inclinado na sua parte superior. Foram selecionados dois ângulos: um de $15 \mathrm{e}$ outro de 30 graus, conforme figura 8 . A partir da incidência da luz nestas superfícies inclinadas será refletido a luz e geradas as sombras, de acordo com sua direção.

Figura 8: Módulo com ângulos de 15 e 30 graus.
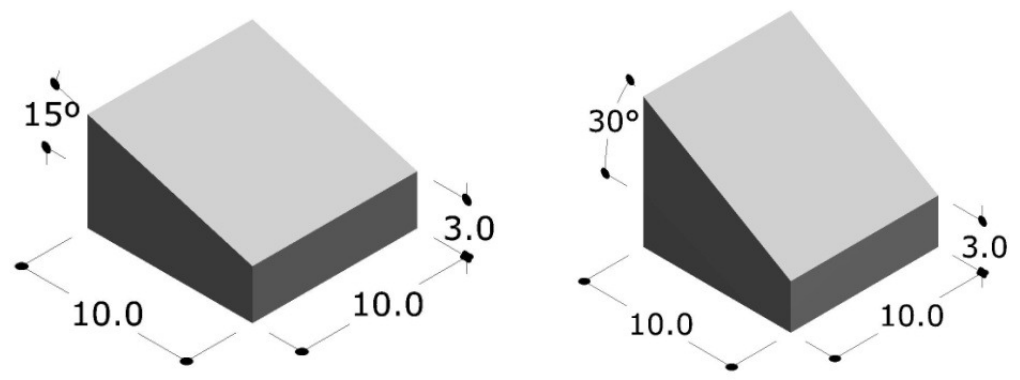

Fonte: elaborada pelos autores (2018). reproduzida.

O segundo parâmetro escolhido foi a complexidade da imagem a ser

Conforme Joly (1996 p.13), cita em seu livro A introdução à análise da imagem, o Filósofo Grego Platão definiu imagem como:

“... primeiramente [as] sombras depois [os] reflexos que se vêem nas águas ou na superfície dos corpos opacos, polidos e brilhantes, e a todas as representações semelhantes".

Foram consideradas duas imagens, uma de complexidade baixa, ou seja, dois círculos concêntricos que servem para analisar a capacidade do painel de representar curvas. E como imagem de complexidade alta, foi selecionada uma imagem com letras em três diferentes tamanhos, similar àquelas usadas para testes de visão (figura 9). 
Figura 9: Imagem de complexidade baixa (esquerda) e imagem de complexidade alta (direita).

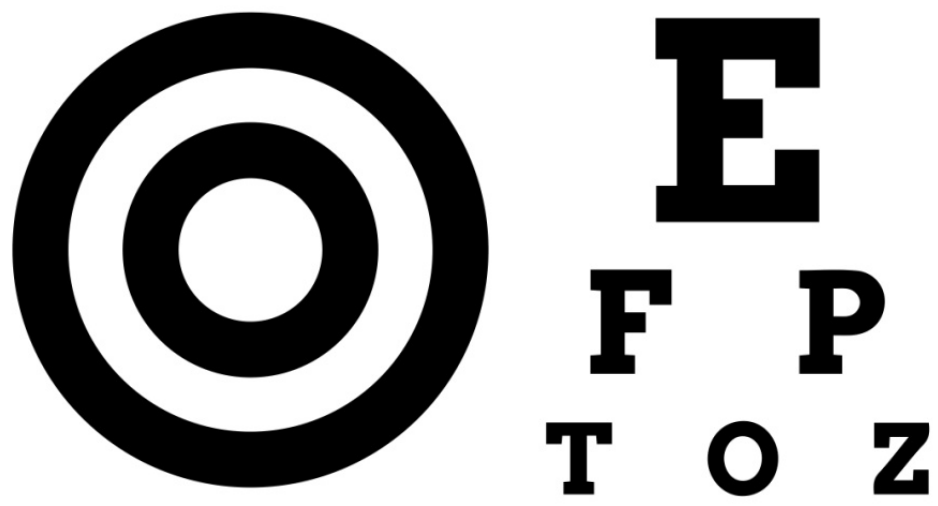

Fonte: elaborada pelos autores (2018).

0 terceiro parâmetro escolhido foi a opacidade do material. Esta propriedade está relacionada à propagação da luz visível, ou seja, quando a luz encontra uma superfície opaca forma-se por trás dela uma área sem luz a chamada sombra. E por isso os objetos não podem ser vistos através das superfícies.

Para tanto, foi considerado um material com baixa opacidade e outro com alta opacidade, como mostra a figura 10. Os materiais de alta opacidade: madeira, espelho e cerâmica e baixa opacidade: acetato, aço corten, alumínio composto (ACM).

Figura 10: Imagem de opacidade baixa (esquerda) e imagem de opacidade alta (direita).
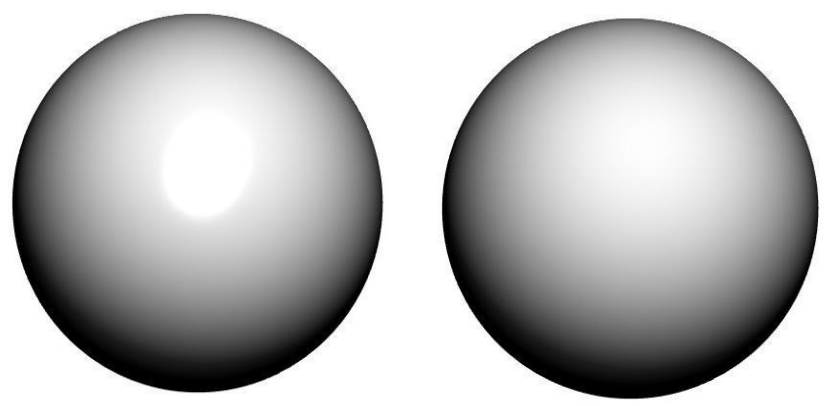

Fonte: elaborada pelos autores.

Depois de definida a seleção de parâmetros e suas variáveis (alta/baixa), o passo seguinte foi a definição do plug-in utilizado e posteriormente a construção do algoritmo. 


\subsection{Grasshopper}

Em 2008 surge o Grasshopper, plug-in do software de modelação tridimensional Rhinoceros, pode ser definido como um ambiente de modelagem visual que gera formas e códigos generativos e scripts. A possibilidade de trabalhar com elementos altamente complexos tem atraído acadêmicos de Arquitetura, Design e Engenharia. Visto que, depois de definidos os parâmetros a serem testados, o Grasshopper acelera o processo de simulações em formas e superfícies. Com isso, diminui-se o tempo que se demandava anteriormente para testar possibilidades.

Atualmente, o software CAD paramétrico oferece interfaces interativas tridimensionais sofisticadas que podem executar variações em tempo real, permitindo que o projetista tenha mais controle e feedback imediato quando um parâmetro é alterado. (HERNANDEZ, 2006, P. 311).

0 autor Kolarevic (2003) reforça a ideia de agilidade no processo de simulações e diz que "os modelos de projeto capazes de transformação consistente, contínua e dinâmica estão substituindo as normas estáticas dos processos convencionais".

No Grasshopper tem-se a construção de algoritmos - definido por Henriques (2016) como ingredientes para a receita de um prato culinário, ou seja, "conjuntos de elementos necessários, com quantidades necessárias, assim como uma sequência de processos que conduzem ao resultado esperado o produto".

A seguir é descrita a construção do algoritmo.

\subsection{A Construção do algoritmo}

Segundo Baxandall (1997), a definição de sombra "...é em primeiro lugar uma deficiência local, relativa, na quantidade de luz que incide sobre uma superfície, e é objetiva. E, num segundo momento, é uma variação local, relativa, na quantidade de luz refletida na superfície para o olho."

Para a construção de uma imagem bicromática, foi necessário em um primeiro momento a combinação de módulos, representado na figura 11. A combinação de módulos 1 tem metade dos seus módulos direcionados ao contrário da luz (seta indicativa no canto superior direito), fazendo com que essa superfície tenha uma deficiência local de luz e, portanto, mais escura. A combinação de módulos 2 , possui a metade de seus módulos a favor da luz (seta indicativa no canto superior direito), gerando um maior contato com a emissão de luz e, portanto, mais clara. 
Figura 11: Combinação de módulos 1 (esquerda) e Combinação de módulos 2 (direita).

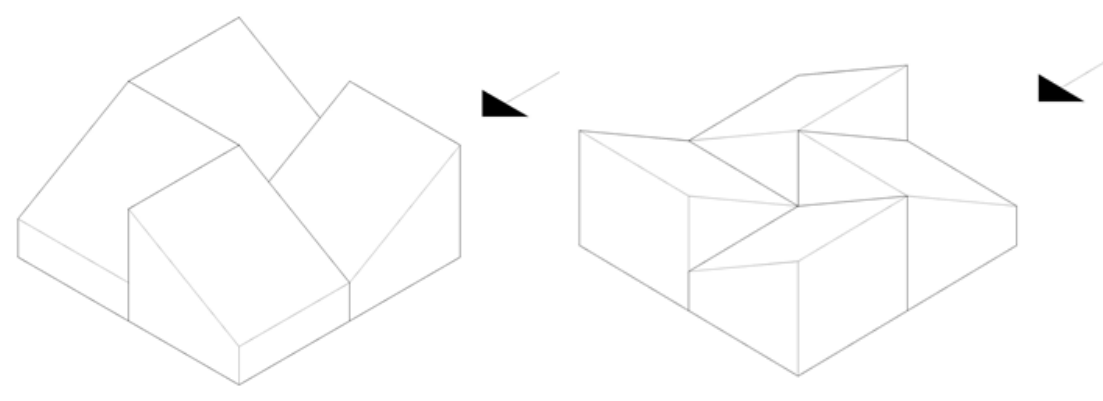

Fonte: elaborada pelos autores (2018).

Após a construção da série de repetições do módulo, iniciada com as medidas escolhidas, os módulos são calculados pelo algoritmo de forma separada, cada um com seu respectivo ângulo de rotação (ex.: $0^{\circ}$ e $90^{\circ}$ no grupo $1 ; 180^{\circ}$ e $270^{\circ}$ no grupo 2 , como numerado na figura 11.

Em paralelo, é criado um painel retangular com o tamanho máximo da repetição gerada previamente. Esse painel serve como referência para a passagem de número 4 na figura, onde os grupos são divididos de acordo com uma imagem bi cromática. Na etapa de número 5 os grupos são rotacionados e por fim, unidos com o componente merge (figura 12).

Figura 12: Imagem do algoritmo criado.

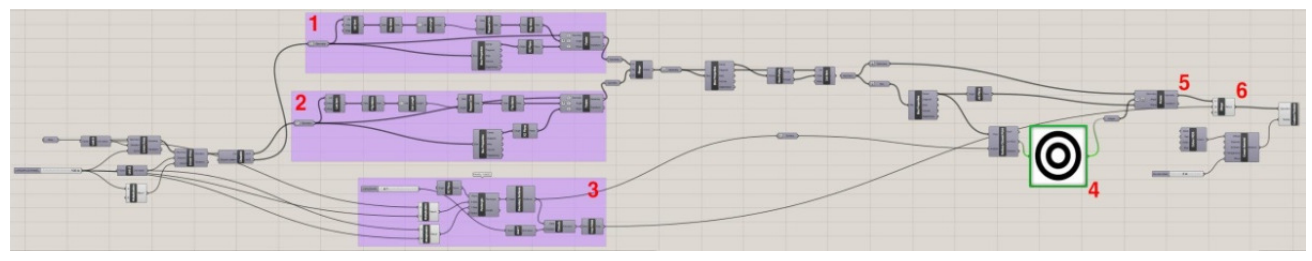

Fonte: elaborada pelos autores.

Ao final da construção do algoritmo foram realizadas as combinações que geraram as simulações descritas a seguir nos resultados.

\section{RESULTADOS}

Inicialmente alguns elementos foram definidos: o dimensionamento do painel (superfície), o ponto de vista (a distância do observador até o painel) e a posição do ponto de luz, conforme figuras 13 e 14 .

Em seguida, os resultados foram divididos em dois grupos: 1) aplicações em ambientes internos e 2) aplicações em ambientes externos. Para cada grupo, a seleção de parâmetros estabelecidas, anteriormente, gerou oito superfícies paramétricas. 


\title{
4.1 Aplicações em ambientes internos
}

Para os ambientes internos, as dimensões estabelecidas para o painel foram de 50x50 centímetros.

\begin{abstract}
As fontes de luz variam em extensão, desde fontes que podem ser consideradas pontuais, passando por vários níveis de fonte estendida, até uma fonte nocionalmente não-direcional admitindo-se infinitas reflexões de luz a partir das superfícies ambientes - chamada luz ambiente. As fontes pontuais produzem a sombra de borda mais marcada; a luz ambiente perfeita não produziria nenhuma. (BAXANDALL, 1997, p. 22).
\end{abstract}

Para que o estudo levantasse uma melhor percepção da relação entre luz e sombra no painel, foi escolhida uma fonte de luz pontual no forro a 20 cm de distância (em ambientes internos). Essa escolha fez com que a sombra fosse mais marcada.

Destaca-se ainda a diversidade de lâmpadas e luminárias para iluminação cênica de superfícies. A escolha da tonalidade da luz que a lâmpada emite, ou seja, a temperatura da cor - luz quente, neutra, luz fria - faz parte de um bom projeto de iluminação. Para trazer aconchego e conforto ao ambiente é importante que estas tonalidades estejam equilibradas, caso contrário teremos ambientes muito dinâmicos e cansativos. Além disso, a escolha da iluminação fria pode distorcer a cor dos objetos.

Se o objetivo da iluminação é dar destaque a uma superfície, pode se optar pelo conceito "wallwashing" com a utilização de spots embutidos (ou sobrepostos) direcionáveis, e lâmpadas AR (70 ou 111 para pé-direito alto).

E para o ponto de vista foram considerados 2 metros de distância (figura 12) para ter um bom ângulo de visão.

Figura 13: Seleção e configuração de elementos para simulação em ambientes internos.

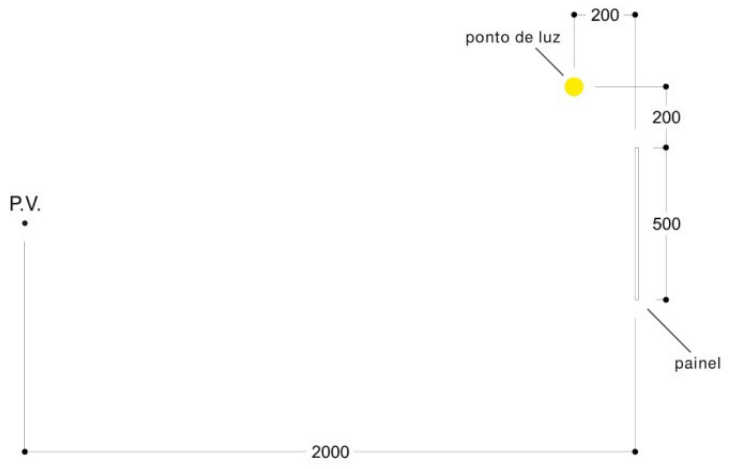

Fonte: elaborada pelos autores.

Na figura 14, são apresentadas as oito combinações geradas pelos parâmetros selecionados para um ambiente interno. 0 gráfico abaixo representa os parâmetros selecionados: 1- ângulo, 2-imagem e 3- opacidade. Nota-se que foram realizadas todas as combinações possíveis. 
Figura 14: Combinações geradas para ambiente interno.
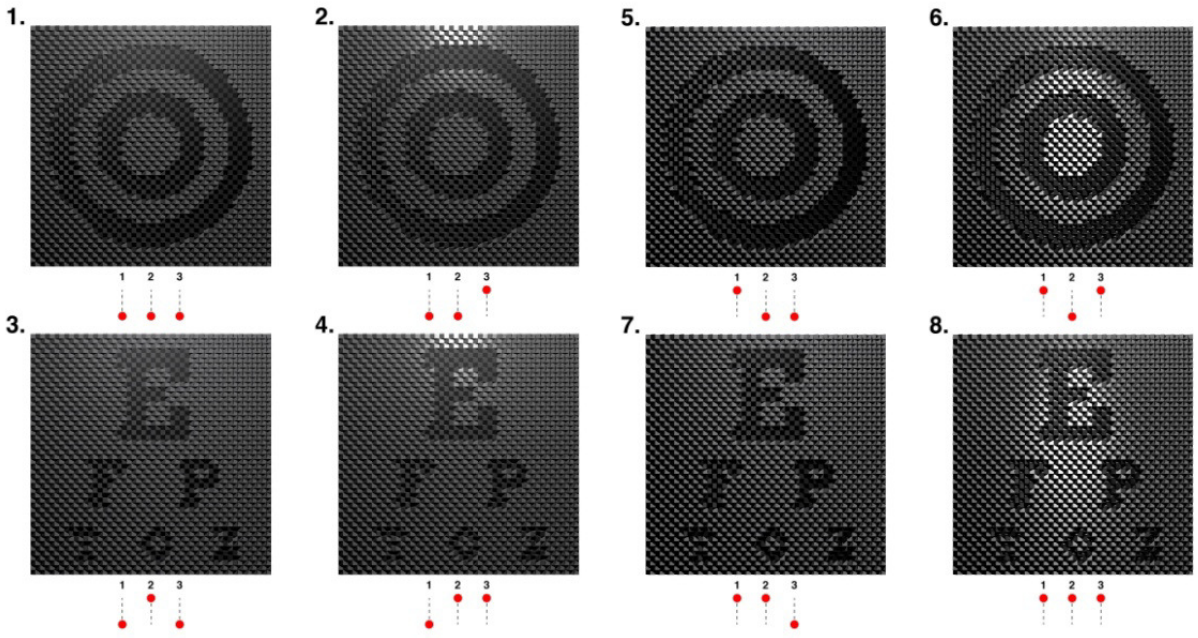

Fonte: elaborada pelos autores.

\subsection{Aplicações em ambientes externos}

Para os ambientes externos, as dimensões estabelecidas para o painel foram de 2,0x2,0 metros. 0 ponto de luz, considerado fixo, está a uma distância de 50 centímetros do painel. E para o ponto de vista foram considerados 10 metros de distância, conforme figura 15.

Figura 15: Seleção e configuração de elementos para simulação em ambientes externos.

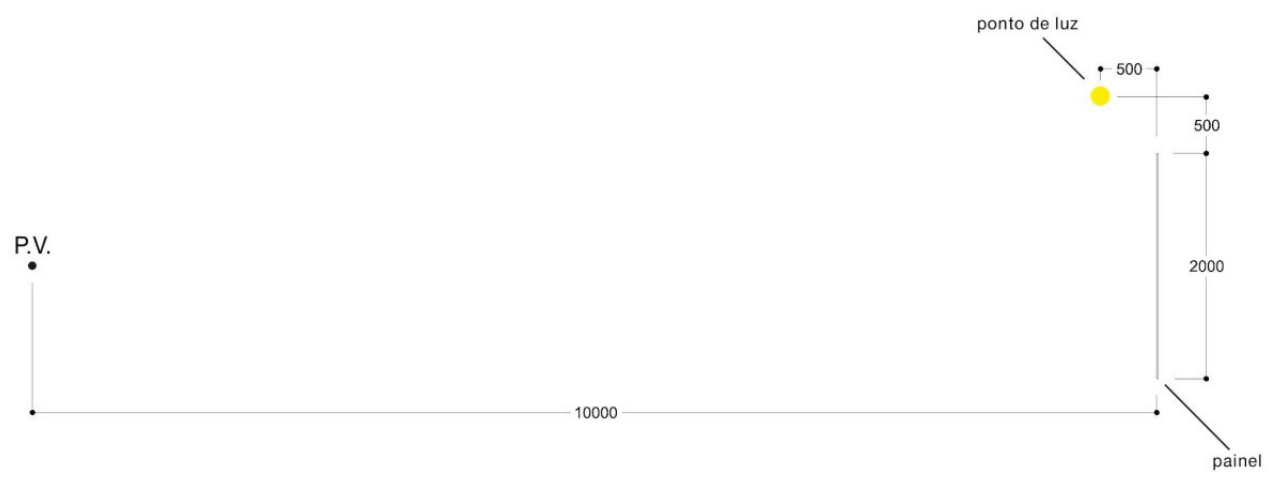

Fonte: elaborada pelos autores.

Na figura 16, são apresentadas as oito combinações geradas pelos parâmetros selecionados para um ambiente externo. 
Figura 16: Combinações geradas para ambiente externo.
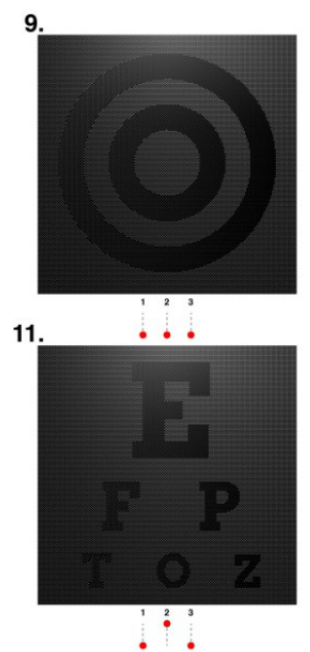
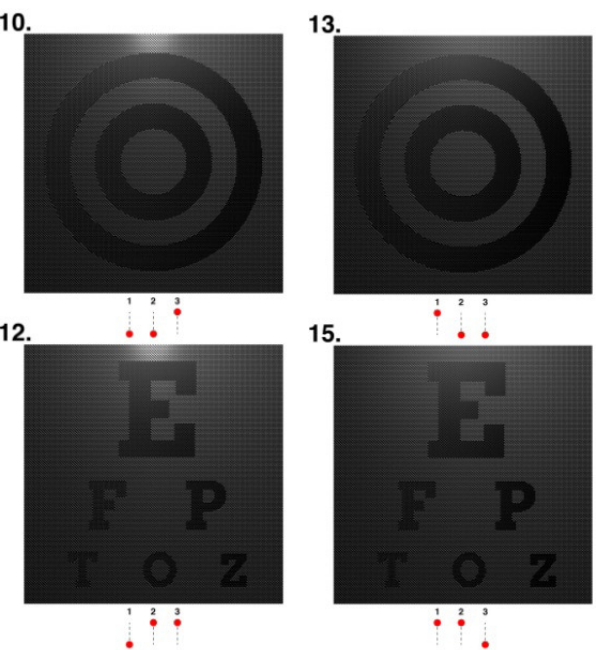
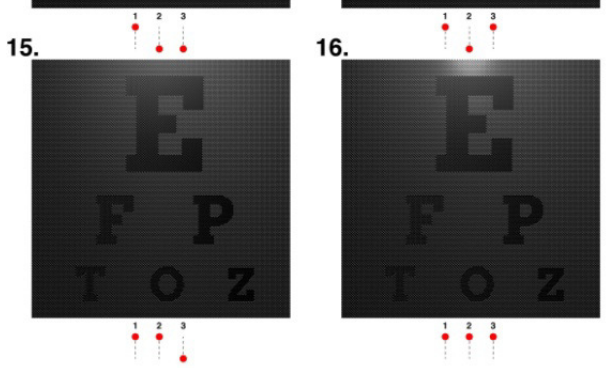

Fonte: elaborada pelos autores.

\section{DIRETRIZES PARA APLICAÇÕES DE PARÂMETROS}

As diretrizes foram organizadas de acordo com os parâmetros estabelecidos e suas relações com os ambientes internos e externos.

\subsection{Em relação ao tipo de imagem}

Nos ambientes internos, os textos são totalmente legíveis a partir de $19 \mathrm{~cm}$ (primeira linha da figura 10 de cima para baixo) e parcialmente legíveis entre 10-19 cm (segunda linha da figura 10 de cima para baixo). Abaixo de $10 \mathrm{~cm}$, não são legíveis e, portanto, não recomendados com essa dimensão de módulo.

\subsection{Em relação ao ângulo do módulo}

0 ângulo de $30^{\circ}$ no módulo aumentou visivelmente o contraste entre as partes claras e escuras em um ambiente interno, sendo ainda mais evidenciado com um material de baixa opacidade. Nos ambientes externos, apesar de o ângulo de $30^{\circ}$ em relação ao de $15^{\circ}$ também gerar um maior contraste entre partes claras e escuras, a diferença não é tão nítida como no ambiente interno.

\subsection{Em relação a opacidade do material}

A baixa opacidade de material (ex. 6, 8, 14 e 16) criou as melhores situações para aplicação de superfícies paramétricas baseadas em luz e sombra. 


\section{CONSIDERAÇÕES FINAIS}

Ao final do estudo, observa-se que a modelagem paramétrica facilita a elaboração de superfícies que, anteriormente, eram criadas de forma individual e isolada.

Com o algoritmo, foi possível a avaliação de múltiplas combinações que ao contrário, dedicaria muito tempo para ser realizada. Depois de analisar todas combinações, foi possível a identificação dos melhores parâmetros para as situações apresentadas (ambiente interno e externo) e a indicação de como aplicar essa técnica de acordo com a finalidade: painéis decorativos, murais, divisórias de ambientes ou fachadas de edifícios.

\section{REFERÊNCIAS BIBLIOGRÁFICAS}

BAXANDALL, Michael. Sombras e Luzes. Tradução: Antonio de Padua Danesi. São Paulo: Edusp, 1997.

GIL, A. C. Como elaborar projetos de pesquisa. 4. ed. São Paulo: Atlas, 2002.

HERNANDEZ, Carlos Roberto Barrios. Thinking parametric design: introducing parametric Gaudi. Design Studies, V.27, n.3, p. 309-324, maio 2006.

JOLY, M. Introdução à análise da imagem. Coleção: Arte \& Comunicação. São Paulo: Edições 70, 1996.

KOLAREVIC, B. (Ed.). Architecture in the digital age: design and manufacturing. New York: Spon Press, 2003.

LE CORBUSIER. Por uma arquitetura. 6a ed. São Paulo: Editora Perspectiva, 2004.

TERZIDIS, Kostas. Algorithmic architecture. 1. ed. Architectural Press, 2003.

ULRICH, Roger S. Effects of healthcare Interior Design on Wellness: theory and recent scientific research. In: Symposium on Healthcare Design, 4, 1991, Boston. Innovations in healthcare design: selected presentations from the first five symposia on healthcare design. New York: Sara O. Marberry, 1995.

VASCONCELOS, Renata T. B. Humanização de ambientes hospitalares: características arquitetônicas responsáveis pela integração interior/exterior. 2004. 177p. il. color. Dissertação (Mestrado em Arquitetura e Urbanismo) Programa de Pós-Graduação em Arquitetura e Urbanismo, Universidade Federal de Santa Catarina. Florianópolis, 2004.

WOODBURY, Robert. Elements of parametric design. Londres: Routledge, 2010. 